\title{
Predicting weather changes
}

\begin{abstract}
Weather changes can be predicted by studing the pressure distribution over a very large surface area on the surface of the Earth. Wind direction and speed can also help in the prediction of the changes that could occur in wether conditions, depending on the surfaces on which these winds track. Winds have been observed to move from high pressure areas to low pressure areas, so analysed pressure charts could help determine the proposed direction of surface winds. Weather changes can bring about many unpleasant life situations, leading from heat to cold; dry to wet; drought to flooding; lightning flashes to thunder and then destructive winds that can cause havoc. Predicting these weather changes is very necessary to air craft's airborne and even human activities on ground. Preparations are needed to be done before the approach of the phenomena that would change the current state of the atmosphere. Meteorological centres are tasked to observe and predict changes in the weather that will occur over a place. Weather products are exclusively produced in codes, colours, and symbols for professionals to interpret in order to protect the truth of the message.
\end{abstract}

Volume 4 Issue I - 2019

Michael Padi
Ghana Meteorological Agency, Ghana

Correspondence: Michael Padi, Ghana Meteorological Agency, P. O. Box 87, Legon - Accra, Ghana Email michaelpadi2000@gmail.com

Received: May 18, 2018 | Published: February 05, 2019

Keywords: hurricane, thunderstorms, meteorologist, weather, atmosphere, satellite

\section{Introduction}

Weather is the state of the atmosphere occurring at a particular place and at a particular time. ${ }^{1}$ The weather over a place can change when the wind changes its direction. ${ }^{2}$ Wind that blows over a very large area is termed as an air mass and it has the capacity to influence the atmospheric conditions when it affects an area. A place that was previously warm could become cold, and vice versa. The direction of the wind can change and it will bring rain. It cans also change and cause haziness. An air mass can be continental or maritime, and they all have their respective effects over the place under study.

For this matter, RGB satellite imageries have been made available to be able to identify particular elements present in the atmosphere, other than observing only the usual clouds and moisture. Dust, Volcanic eruption and thunderstorm activities are those that bring about sudden changes in weather situations. Weather changes are mostly rapid. Rain can just start within a short time and destroy a lot of things. For this reason the atmosphere needs to be monitored, and weather forecast provided for preparation towards safety.

Weather related accidents can be avoided or their effects reduced if weather systems are carefully studied, and results communicated well to end-users. Dissemination of weather information should be paramount, especially in the media, because weather products are mostly technical, and it is important to need a professional to interpret the weather products.

Weather change can have effect on people when they find themselves in deferent environments. It usually occurs when one travels from the tropics to the temperate regions. Weather conditions in these two defined areas are strictly different from one another. It is therefore important to know the weather conditions of the destination before a journey is embarked on. Advice on dress code is very necessary, especially when one is moving into a new environment that has distinct weather change. If the weather would be cold, then jackets and thick pull overs are needed to be prescribed. If the new environment is very hot, then light dresses are needed to prevent too much sweating, and plenty water is needed for hydration. Failure to comply with such practices would result in serious health issues like catarrh, colds and flu.

Weather changes can bring about the invasion of certain insects that can give certain diseases like malaria and fever. Dress codes must be studied and complied in order to prevent insect bites and be able to adapt with the changed situation. It is important to get education on weather changes in order to cope with them. It is also important to know the intensity of the change in the weather that is expected so that relocation could be subjected, if it is the only way to survival.

To be able to predict rain during the dry hazy period is a very important practice. During that time the probability of rain occurring is very low. All that could be thought of, at that time is continues haziness. First rains can be torrential and are mostly on localized basis, they normally occur over small areas. Roofs can be ripped off, trees uprooted, and many associated dangers, including flooding occur when the weather changes. These conditions mostly occur during the weather transition periods where one set of weather conditions change completely to the other. It is important to be able to predict the beginning of the hazy conditions as well before it starts or to then predict the return of the hazy conditions after it has gone and it started raining.

Studies of pressure systems around the continents help in predicting weather conditions and changes in weather over the land. Meteorologists over every country have studied the pressure systems around them and developed strategies in analysing them to come out with weather predictions. Continuous examination of satellite products, like the satellite imagery, is another strategy of monitoring the atmosphere and predicting weather changes.

Human activities can have serious effect weather, so human effects are considered in models that are used in predicting the state of the atmosphere. ${ }^{3}$ Certain atmospheric constituents that may affect the production of clouds might be injected into the atmosphere by human beings and if not considered would then give a different output from 
the models. Carbon dioxide which is a greenhouse gas, and mostly produced by vehicles and machinery, warms the atmosphere and reduce cloud patterns.

If a forecast is made for a particular place, and a farmer over that same area decides to seed clouds after the forecast so that there could be rain on his farm; the forecast would then be erroneous because the seeding effect has not been factored into the models. ${ }^{4}$ Seriously, it would be an attack on the forecast.

For a model to be a good model, then it should be able to understand the behaviour and the constituents of the atmosphere. Its greenhouse effects have to be included in the algorithms. Satellite measurements of certain trace gases and elements have to be considered. NOAA, ECMWF, UKMO, and Meteo France are examples of model producers that have served the meteorological community over the years.

EUMETSAT has been able to monitor the atmosphere over Africa, and produced near real-time products that have helped in tracking tropical storms over the years. When fair weather changes to stormy weather it then becomes an issue where people would lament on. Normal activities and schedules are most of the time affected when the weather changes. Weather can change and would result to intensification of hazy conditions, where visibilities will deteriorate; the changes can also be the other way round where it can bring about comfort.

Hazy conditions are expected and experienced mostly in December over West Africa. If it is December and it has still been raining instead of the usual haze, it then raises a lot of alarm. The return of the haze over West Africa is usually in April, but in 2018 it happened close to the end of March. Meteorologists are able to detect the approach of the dust from the time it was raised from the ground (Figure 1).

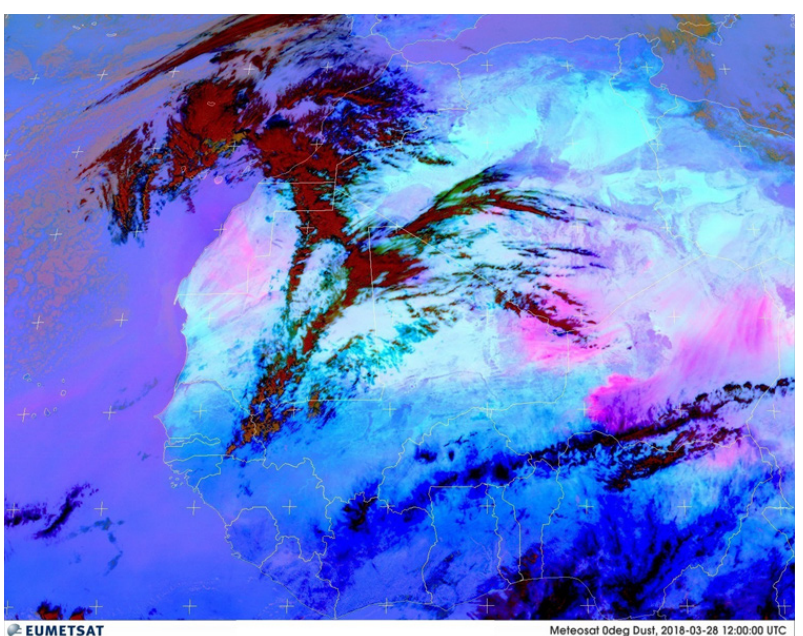

Figure I Satellite imagery showing the approach of dust storm (magenta colour) from the Sahara Desert towards Nigeria, and then to Ghana ${ }^{5}$ on the $28^{\text {th }}$ March, 2018 at mid-day.

There are so many products that describe the atmosphere when making forecast and the choice of product greatly influences the forecast.

Unusual weather conditions could sometimes be favourable but scientists would like to think of consequences that it may bring in future. Some consequences could be whether the coming Haze or rain or snow would be severe or mild, its duration and other climatic influences that it may have over a place. Convective activities can be violent and devastating, they can occur over small areas without attracting much attention of weather observers (Figure 2).

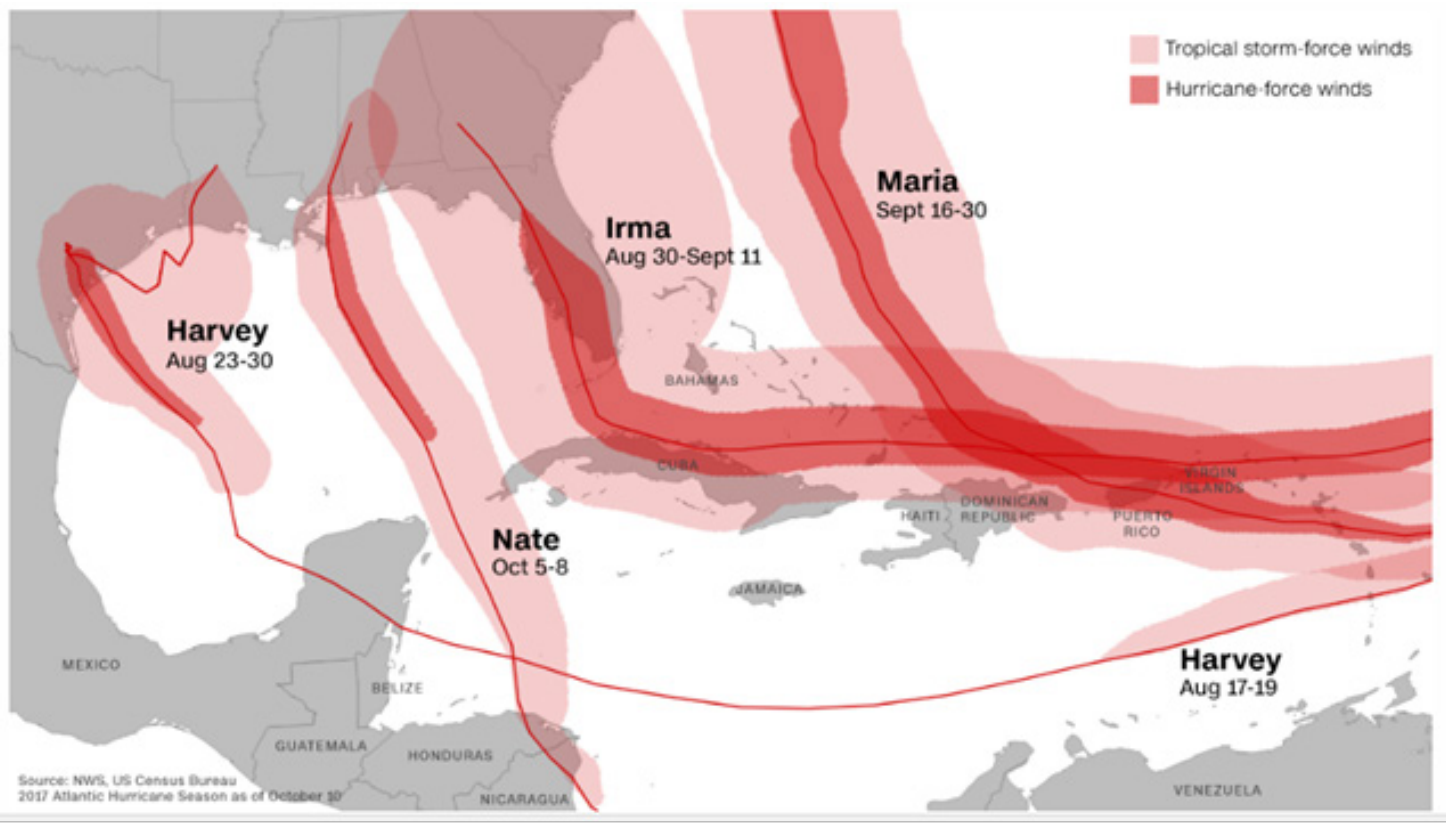

Figure 2 A look at four storms from one brutal hurricane season6 that affect the Caribbean in 2017 where weather changed and brought disasters.

Weather changes are mostly seasonal and occur at regular times over places, for instance, hurricanes have their seasons. Within August and September, 2017 four severe hurricanes affected and devastated the Caribbean. Harvey, Nate, Irma, and Maria are highly intense hurricanes that people attribute to climate change. Their frequencies of occurrence and intensities were observed to reach the highest.?
During and after hurricane periods the general public is advised to keep listening to radio and TV for weather advice. They are advised to wait until an area is declared safe before entering, watch out for closed roads in order to prevent drowning. They are also advised to stay on firm; dry grounds since moving water, only 6 inches can sweep off feet. Standing water may be electrically charged from power lines. Do 
not drink or prepare food with tap water until officials say it is safe, then wear proper shoes to prevent cutting feet on sharp debris. ${ }^{8}$

Weather services are mostly for safety purposes. When one finds his or herself in a dry environment, with high temperatures as it is in the northern sector of Ghana, then drinking more water and staying in flooded rooms, by pouring water on the grounds would be another form of remedy. Burnings in the nose is another form health issue that is associated with dry conditions.

Any locality has its peculiar type of climate that dictates its weather conditions. Squalls and thunderstorms are forms of weather changes that are mostly devastating in Ghana. Weather changes affect people's attitude in dressing and even feeding, to mention a few. People tend to throw rubbish into the gutters when it is raining, and it gets stuck in front of someone's house and water cannot flow. Flooding would then start from that locality and spread into the community.

\section{Materials and methods}

The idea of predicting the weather starts with knowing what is around you, at the point of observation or the area in question. Physical atmospheric observations and other thermal departures give an insight of the future weather. On a cloudy night with cool breeze, and associated lightning to the East is a sign of rain occurring, especially over areas within the Tropics. The atmosphere must be a concern, whether misty or foggy, raining or shining, are forms of weather conditions that needs to be alert of, for safety reasons. The choice of location is greatly challenged by hash weather events whenever they occur. Successive satellite imagery monitoring (animation) is one best way of tracing weather events and making now casting. Other extended forecasts, which are forecast models, depend on equations that predict value of elements in the atmosphere. These are the products that the Meteorologist would have to interpret before coming out with a forecast.

Winds usually blows from the high pressure area to the low pressure area, so the direction and speed of the wind, and where it tracks are things that are factored before coming out with a forecast. Cloud observation is very vital and it can suddenly change the weather of a place. It can block the rays of the sun and create a shadow to reduce temperatures during the day. Certain clouds can grow to form thunder clouds so cloud identification is very paramount in predicting weather events. Where clouds are absent, day time temperatures reach the extreme.

\section{Results and discussion}

It is a fact that weather related events have taken lots of life and property during the previous era when computers and satellites were not so common, but now in the $21^{\text {st }}$ Century, weather related deaths are registered to be on the decrease. ${ }^{9}$ These are confirmations that the World Meteorological body is actively productive in terms of weather information to the public and decision makers. Weather information relating to forecasts is readily available on hand held devices and the internet. Weather institutions have found it very necessary to get weather information to the general public through 'social media' and it has helped a lot.

On the weather charts, local weather forecasters have local synoptic features in describing elements when making forecasts. For instance, the "Libyan High, Mid Latitude Trough, Equatorial Trough" is terms which usually describe weather events that are likely to occur over a particular place. The extension of the Mid Latitude Trough over North
Africa is a sign of bringing rain to West Africa. The establishment of the Libyan High is a manifestation that dust would be raised from the Sahara Desert and transported to West Africa to produce Haze (Figure $3)$.

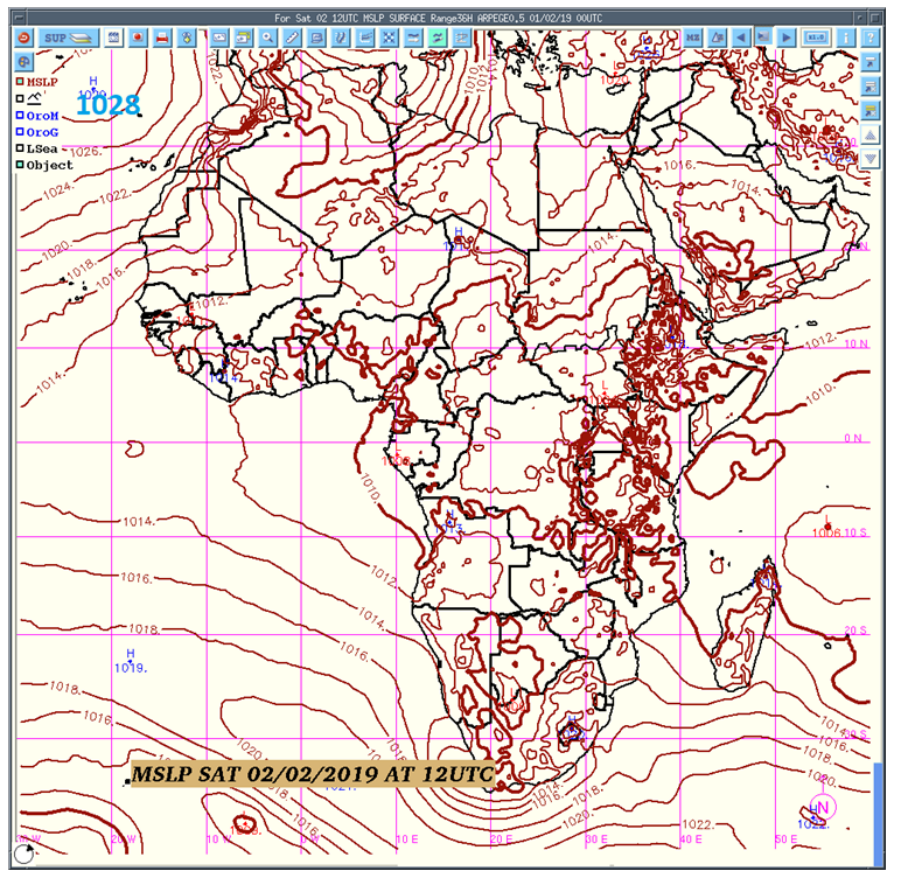

Figure 3 Surface Pressure Chart for Saturday, 02/02/2019 at I200 UTC showing isobars, where the extension of a low pressure system (Mid Latitude Trough) extends from Europe into North Africa allowing lots of moisture into West Africa.

\section{Conclusion}

It is very necessary to stay indoors when the weather has changed or is changing to be hash. In times of gusty winds tree branches could fall off and even some uprooted. It is therefore safe to stay away from trees when it is windy. Lightning can easily kill so it is good to stay indoors when there is serious lightning and thunder.

Humans have greatly influenced the current climate of ours, carbon dioxide gas is on the increase and global temperatures are rising. It is the responsibility of everyone to protect the environment so that the future climate could be habitable. The attitude of reducing fossils and encouraging renewables is the only fate of preventing weather related fatalities in the future.

\section{Acknowledgments}

None.

\section{Conflicts of interest}

Author declares there is no conflicts of interest.

\section{References}

1. Weather.

2. Why does weather change?

3. Modeling human impact on global warming.

4. Weather modification. Cloud seeding.

5. Eumetsat. Monitoring weather and climate from space. 
6. Therese Malbon. A look at four storms from one brutal hurricane season 2017.

7. Training peaks. How to dress for changing weather.
8. After the storm. 2017.

9. Weather-related fatalities in the United States. 